\title{
Relationship between the perception of classroom learning environment and student academic emotions
}

\author{
Lira Fessia Damaianti ${ }^{1}$, Risda Awaliya ${ }^{2}$, Ifa Hanifah Misbach ${ }^{3}$ \\ ${ }^{1}$ Departement of Psychology, Universitas Pendidikan Indonesia
}

\author{
Article Info \\ Article history: \\ Received Aug $20^{\text {th }}, 2019$ \\ Revised Oct $23^{\text {th }}, 2019$ \\ Accepted Dec 30 ${ }^{\text {th }}, 2019$ \\ Keyword: \\ Perception of classroom learning \\ environment \\ Academic emotions \\ Learning model \\ Educational psychology
}

Corresponding Author:

Lira Fessia Damaianti,

Email:1fdamaianti@gmail.com

\begin{abstract}
Perception of classroom environment and academic emotions have an important role in the educational context. Both have a relationship that can not be separated from each other. This study aims to examine the correlation between perception of classroom learning environment and academic emotions in junior high school students in the city of Bandung. Using the quasy experimental method with a quantitative approach with a correlational design with a sample of 81 respondents aged 12-14 years who were selected using a purposive sampling technique. The instruments in this study consisted of academic emotions questionnaire (AEQ) and my class inventory (MCI) that had been translated into Indonesian. Data analysis was performed using the Pearson product moment. The results showed a positive correlation between the dimensions of competitiveness with negative academic emotions and a negative correlation between the dimensions of satisfaction with negative academic emotions in junior high school students in the city of Bandung.
\end{abstract}

C 2019 The Authors. Published by Indonesian Institute for Counseling,

Education and Therapy (IICET). This is an open access article under the CC

BY license (https://creativecommons.org/licenses/by/4.0/)

\section{Introduction}

The Perception can be defined in more than one way. This is often narrowly defined as awareness of objects and events in the environment (Norman, 2002). Perception is a constructive process in which people pass stimuli that are physically present and try to form a useful interpretation, by which individuals can recognize, organize, and understand uptake through sensory devices received from stimuli in the environment (Feldman , 2012; Strenberg \& Strenberg, 2012). According to Feldman (2012) perception processes in two different ways, called top-down and bottom-up processing. Top-down processing is perception directed by knowledge, experience expectations, and motivation at a higher level, whereas bottom-up processing is perception consisting of advances in experience and information processing from the individual components of a stimuli turn to perception as a whole. This leads to a form of social environment, especially in education known as the Classroom Learning Environment. Classroom Learning Environment is defined as the social environment, psychological environment, or psychosocial environment where teaching and learning takes place (Radovan \& Makovec, 2015). The environment and features in the classroom play a major role in improving the learning and teaching process in schools and are identified as the main determinants of student learning success (Amirul, et al., 2011). Knowledge of the environment is able to stimulate students to be involved in the learning process and can influence student behavior and to assist in the development of their skills or cognitive perceptions. So that it will bring up various perceptions in student learning styles that are adapted to the environment. Perception of classroom learning environment is a variable that influences students' cognitive processes and academic achievement, and plays an important role in promoting student motivation and cognition (Abolmaali \& Mahmudi, 2013). Perception of classroom learning environment refers to how students and teachers see various aspects of the learning situation in their classrooms (Tshewang, 2015). Perception of classroom learning environment can be positive or negative. 
Positive perceptions reflect positive feelings, emotions, attitudes, and positive views of someone towards something or someone, and negative perception refers to negative feelings, emotions and attitudes towards something or someone (Tshewang, 2015). According to Fraser's perception of classroom learning environment it is very important to understand the learning opportunities provided for each student in the class. In other words, this paradigm assumes a better understanding and improvement of teaching and learning can emerge by examining the ways that classroom instruction and learning environments are seen or interpreted by students (Padron, et al, 2012).

Middle school students are students who are undergoing a transition from elementary school (SD) to junior high school (SMP). 7th grade junior high school students are in early adolescence with an age range of 12-14 years (Papalia, et al., 2008). Santrock (2007) states that in this transition period students experience a top-down phenomenom, which is the condition of change from the oldest, strongest and biggest student in elementary school to the youngest, smallest, and weakest student in junior high school. According to Eccles when students enter junior high school they often assume that schools are unattractive and unimportant (Gentry \& Gable, 2001). Hill \& Mobley (2015) opinion the transition from elementary school to secondary school is a critical period which is considered one of the most difficult things for students. They can experience several negative effects during the transition period, including anxiety, stress, fear, and anxiety. In the opinion of Gentry \& Gable (2001) changes in the learning environment that occur from elementary to junior high can influence changes in academic motivation, achievement, and student behavior. There are several things that can influence students in their interest in learning, involvement in class, affect the social climate in the classroom, and improve academic achievement, one of which is academic emotions (Rita \& Paola, 2014). The understanding of academic emotions is the emotional experience of students in the process of achieving achievement in schools and universities, both emotions related to success or failure (Pekrun, et al., 2002). Pekrun assumes that academic emotions have a certain effect on learning activities and achievements based on classification according to valence and activation. (Villavicencio, 2011).

Valence, which is a positive or negative direction that describes the emotions felt by individuals towards an event (Paoloni, et al., 2014). According to Greensfeld \& Nevo (2017) revealed that this emotional valence arises during the learning process takes place. While activation according to Paoloni, et al., (2014) refers to a single activation state or emotional arousal that depends on one's physiological condition in responding to the emotions experienced by that person. Pekrun (2017) classifies the academic emotions classification with valence and activation into four models, namely positive-activating (enjoyment, hope, pride); positivedeactivating (relief); negative-activating (anger, anxiety, shame); and negative-deactivating (hopelessness, boredom) (Villavicencio, 2011). Positive activating emotions (enjoyment, hope, pride) are considered to be able to increase cognitive power and focus students' attention on learning, support interests and increase intrinsic motivation, and facilitate deep learning. Thus, this emotion is expected to positively influence student academic achievement even under the pressure of school work. The opposite effect is negative deactivating emotions (boredom, hopelessness), these emotions are considered to reduce the cognitive power and attention associated with the task, reducing students' intrinsic and extrinsic motivation. Thus, negative deactivating emotions are considered to be able to negatively affect student achievement. Deactivating positive emotions (relief) is considered to reduce student attention and effort, but can strengthen long-term motivation to return to learning. Activating negative emotions (anger, anxiety, shame) are considered to reduce cognitive power by encouraging irrelevant thoughts, such as concerns about failure in tests, anxiety, and reducing intrinsic motivation (Pekrun, et al., 2017).

Students in the school environment experience a myriad of emotions every day (Greensfeld \& Nevo, 2017). According to Zadra \& Clore (2012) emotions are the result of perceptions about the environment, where perceptions can affect emotions and behavior as a result of emotional reactions. Based on the results of research conducted by Lam, et al., (2015), it is recommended to pay attention to the variables of the school environment where learning is due to positive emotions such as enjoyment, hope, pride that may arise when students perceive the school environment where they learn positively. According to Langton, et al., (2010) explains that perception is a process used by individuals to organize and interpret sensory impressions to give meaning to their environment. The environment can influence individual development through biological and psychological characteristics, talents and abilities and temperament. Individuals develop through systems that influence each other through social interactions both within families, schools and communities that have an impact on how parents, teachers and communities should nurture and educate children holistically (Berns, 1997). Based on the ecological theory developed by Bronfenbrenner revealed that the environmental context can influence individual development. The reciprocal relationship between the 
individual and the environment that will shape the behavior of the individual. Ecological theory views the development of children from three environmental systems namely micro systems, ecosystems, and macro systems. School environment and classroom learning places included in the micro system in ecological theory (Mujahidah, 2015). In this study focused on the classroom environment where learning at school, based on ecological theory developed by Bronfenbrenner, the school environment is included in the micro system. Microsystems are environments where individuals live, these connections include individual families, peers, schools and neighborhoods. In micro systems direct interaction occurs with social agents, such as with parents, peers, and teachers. Interactions that occur in individual microsystems are not passive recipients, but actively participate in shaping and building micro system settings (Kamenopoulou, 2016).

The classroom environment where learning provides opportunities for students to develop a sense of personal competence and autonomy as well as positive relationships with others (Wang \& Holcombe, 2010). A number of studies have clearly shown that the classroom learning environment is significantly related to student academic achievement (Frenzel, et al., 2007). According to Fraser \& McRobbie academic achievement has become the number one variable considered as a result of perception of classroom learning environment (Frenzel, et al., 2007). In addition, other findings show that most of the perception of classroom learning environment has an affiliation and as an extrinsic motivation (Wei \& Elias, 2011). Perception of classroom learning environment is a variable that affects students' cognitive processes and academic achievement, and plays an important role in promoting student motivation and cognition (Abolmaali \& Mahmudi, 2013). Sink \& Spencer (2016) there are five things that can assess students' perceptions individually to measure the classroom environment where learning as a group, including cohesiveness, conflict (frictions), satisfaction (statisfaction), and competitiveness (competitiveness). Yalom (2005) cohesiveness is very important to support people in times of conflict and causes extreme discomfort. The cohesiveness of group members can create warmth, comfort, and a sense of belonging. Besides that students who think that conflicts (friction) often occur in class have low resilience, because students feel they have less support from teachers and classmates (Padron et al., 2012). According to Anttila, et al., (2017) such conflicts arise, when a student loses his interest in learning or feels that the teacher is not providing adequate support. This often results in incompetence, disappointment, frustration, boredom or fatigue. In addition, satisfaction is at the highest level when students feel that activities in the classroom are well organized and the teacher is very supportive and allows students to be actively involved in their learning (Radovan \& Makovec, 2015). According to Lens, et al., (2005) competitiveness that occurs in the classroom shows that the presence of competing activities can disrupt students in learning, and explain their low effort.

\section{Method}

This research uses a quantitative approach with a correlational design. Participants in this study were junior high school students in the city of Bandung aged 12-14 years. Sampling in this study using nonprobability sampling techniques. This study involved 817 th grade junior high school students in the city of Bandung. The perception of classroom learning environment measuring instrument is adapted from Fraser (1998). The measurement tool for perception of classroom learning environment is my class inventory short form (MCI-SF). This instrument consisted of 17 items and filled out questionnaires. In measuring the academic emotions of researchers adapted from Pekrun et al., (2011). The academic emotion measurement tool is the academic emotions questionnaire (AEQ) compiled by Pekrun et al., (2011). This instrument consisted of 61 items and filled out questionnaires. Data analysis techniques in this study used Pearson product moment correlation analysis techniques to determine the correlation (degree of adhesion) between academic emotions as variable $\mathrm{X}$ and perception of learning environment as variable $\mathrm{Y}$. This technique was carried out because the ordinal data generated by the two variables had been converted to scale. ratio using the Rasch model with Winsteps software. This technique is used to test the researchers' assumptions that academic emotions and perception of classroom learning environment have a significant correlation.

\section{Results and Discussion}

\section{Relationship between Perception of Classroom Learning Environment and Academic Emotions}

Based on the correlation between perception of classroom learning environment with academic emotions, it is known that there are only two correlations, namely the correlation between the dimensions of competitiveness and negative academic emotions with a correlation coefficient of 0.199 and Sig. (1-tailed) of 
$0.037(<0.05)$. Second is the correlation between the dimensions of satisfaction and negative academic emotions with a correlation coefficient of -0.201 and Sig. (1-tailed) of $0.036(<0.05)$. The correlation coefficients in both are included in the low category, this can occur because there are other factors associated with perception of classroom learning environment and academic emotions.

Table 1. Correlation results between perception of classroom learning environment and academic emotions

\begin{tabular}{lcc}
\hline \multicolumn{1}{c}{$\begin{array}{c}\text { Perception of Classroom Learning } \\
\text { Environment }\end{array}$} & \multicolumn{2}{c}{ Academic Emotions } \\
\cline { 2 - 3 } & $\begin{array}{c}\text { Positive Academic } \\
\text { Emotions }\end{array}$ & $\begin{array}{c}\text { Negative } \\
\text { Academic } \\
\text { Emotions }\end{array}$ \\
\hline Cohesiveness & & -0.138 \\
& Sig. 0.109 \\
Competitiveness & Sig. 0.223 & $0.199^{*}$ \\
Friction & -0.042 & Sig. 0.037 \\
Satisfaction & Sig. 0.355 & 0.148 \\
& -0.045 & Sig. 0.094 \\
& Sig. 0.343 & $-0.201^{*}$ \\
\hline
\end{tabular}

Based on the table above, it is known that the correlation value between negative academic emotions with competitiveness is equal to 0.199 * which means there is a positive correlation with the value of Sig. (1tailed) of $0.037(<0.05)$ means that the correlation is significant at the 0.05 significance level. A positive correlation occurs between the dimensions of competitiveness with negative academic emotions. When viewed from the process of academic emotions, in the process there are controls related to cognition that can focus directly on cause-and-effect relationships (eg expectations of action-results) and indirectly refer to conditional relations between personal characteristics and contingency outcomes. One of the most important types of cognition in control-related perceptions is the assessment of one's competence or competitiveness, or also referred to as perceived competitiveness (for example, self-concept ability and self-efficacy expectations). Subjective values involved in self-appraisal can be intrinsic or extrinsic, for example good grades might be appreciated by students who are intrinsically motivated to achieve them, and may also be very important for other students who are motivated by extrinsic goals such as how these grades will help to get a good job in the end. Subjective-control and subjective values are proposed to mediate the relationship between emotional experience and environmental aspects specifically related to (a) competence support, (b) autonomy support versus control, (c) achievement expectations and goal structures, (d) achievement outcomes and feedback, and (e) social relatedness. Student emotions can influence their cognitive assessments so they better assess their own competencies when they experience positive academic emotions. In this case, emotions can be considered as antecedents of aspects in the social environment of students (Goetz et al, 2006).

Based on Table 1, it is known that the correlation value between negative academic emotions with satisfaction that is equal to -0.201 * means there is a positive correlation with the value of Sig. (1-tailed) of $0.036(<0.05)$. Satisfaction (satisfaction) is at the highest level when students feel that the activities in the classroom are well organized and the teacher is very supportive and allows students to be actively involved in their learning (Radovan \& Makovec, 2015). Based on the results of research Kolak \& Reflection (2015) revealed that satisfaction is an emotional response to reduce boredom and despair. Boredom and hopelessness are included in the example of negative academic emotions, hopelessness related to lack of hope. Students who have feelings of despair are those who do not hope optimistically to achieve what is desired in class (Paoloni et al., 2014).

Boredom (boredom) refers to the unpleasant feeling of feeling tired or tired of staying in class. Generally a natural situation is felt which makes it difficult to pay attention or participate in the tasks requested. Students who are bored in class have problems in paying attention, concentrating, finding meaning from assignments, working hard, and overcoming difficulties (Paoloni et al., 2014). Perception of classroom learning environment is a variable that can affect academic achievement and cognitive processes of students, besides this variable has an important role in promoting student motivation and cognition (Gentry, et al. 2013). Perception of classroom learning environment can be positive or negative. Positive feelings, emotions, attitudes, and positive views of someone towards something or someone is an example of positive perception, and negative perception refers to negative feelings, emotions and attitudes towards something or 
someone (Tshewang, 2015). Perceptions owned by each individual will be different, because each individual has a way to interpret an object depending on the individual's point of view (Strenberg \& Strenberg, 2012). Grading values on objects, helping ways to recognize things, and providing motivation to do things is emotional (Zeelenberg, et al., 2008). Emotions are the result of cognitive evaluations that produce internal and external signals and a corresponding set of actions (Holodynski, 2013).

Emotions in the context of learning, emotions associated with learning, teaching, and achievement are known as academic emotions (Scholae, 2013). Academic emotions have an impact on student achievement as well as their personality, involvement and personality development besides influencing the social climate in the classroom and educational institutions (Rita \& Paola, 2014). The emotions that individuals have will vary depending on the composition of emotions they have, the composition of emotions consists of arousal or in academic emotions known as activation (activating) and valence. Arousal is the level of activation produced when stimulus is encoded, which varies from calm (low) to passionate (high) Valence is the level of pleasure generated when the stimulus is encoded, which varies from very negative to neutral to very positive (Gomes, et al., 2013). emotions are controls that bind to cognition and can at focusing directly on cause and effect relationships. The low correlation obtained by the perception of classroom learning environment and academic emotions is thought to have other factors associated with these two variables. One factor related to academic emotions is school belonging. Based on self-determination theory, school belonging may stem from an inner need to develop connections with others and a sense of group identity (Deci, et al., 2017). In addition, students who feel connected and accepted at school are also less likely to experience negative disabling emotions, including helplessness, fatigue, boredom, and depression, deficiencies that might also increase their academic success (Lam, et al., 2015).

\section{Positive Relationship between Cohesiveness and Positive Academic Emotions}

Based on Table 1, it is known that the correlation value between positive academic emotions with cohesiveness is equal to 0.086 which means that both variables have a very low positive correlation. In addition, the value of Sig. (1-tailed) of 0.223 (>0.05) means that the correlation is not significant at the 0.05 significance level. This means that there is no positive correlation between cohesiveness and positive academic emotions. The lack of correlation in this study is suspected because there are other factors associated with cohesiveness and positive academic emotions. Factors related to cohesiveness include commitment by group members, commitment to group (attachment person-to-group) manifested in collective oriented behavior on behalf of the group and towards its members, for example more favorable, cooperative, or cooperative behavior. generous. (Lawler \& Thye, 2000). Yalom (2005) revealed that the cohesiveness of group members can create warmth, comfort, and a sense of belonging. According to Lawler \& Thye (2000) emotional valence influences individuals to make conclusions about cohesiveness. The emotional consistency of group members influences conclusions and shared fate assessments about group responsibilities

\section{Negative Relationship between Positive Competitiveness and Academic Emotions}

Based on Table 1, it is known that the correlation between positive academic emotions and competitiveness is $-0,042$ which means that both variables have a negative correlation. In addition, the value of Sig. (1-tailed) of 0.355 (> 0.05) means that the correlation is not significant at the 0.05 significance level. This means that there is no negative correlation between competitiveness and positive academic emotions. There is no correlation in this study, it is suspected there are other factors related to competitiveness and positive academic emotions. Factors related to competitiveness are the involvement in certain activities (engagement), the involvement of students in certain activities and their efforts not only depend on the strength of motivation for certain types of activities (for example, learning) but also on the amount and strength of the tendency of action to power compete. Thus, students adopt a more dynamic perspective on motivation, because they do not consider activities (and motivations) separately, but pay attention to dynamic and continuous interactions between behaviors over time (Lens, et al., 2005). According to Lens, et al., (2005) competitiveness that occurs in the classroom shows that the presence of competing activities among students can interfere with students in learning, and explains that their efforts are low.

\section{Negative Relationship between Friction and Positive Academic Emotions}

Based on table 4.7, it is known that the correlation between positive academic emotions and friction is 0.045 , which means that both variables have a very low negative correlation. In addition, the value of Sig. (1tailed) of 0.343 (>0.05) means that the correlation is not significant at the 0.05 significance level. This means that there is no negative correlation between friction with positive academic emotions. There is no 
correlation in this study, it is suspected there are other factors associated with friction and positive academic emotions. factors related to friction include resilience, which is a multidimensional construction (Cicchetti, 2014), and this is the ability to overcome the most difficult problems and overcome the most complex situations (Cicchetti, 2008). This represents a person's capacity to tolerate catastrophic events. Resilience enables people to overcome their traps and overcome complex situations. Students who consider that conflicts often occur in classrooms have low resilience, because students feel they lack the support of teachers and classmates (Padron et al., 2012). According to Anttila, et al., (2017) such conflicts arise, when a student is released from learning, loses his interest in learning or feels that the teacher is not providing adequate support. This often results in incompetence, disappointment, frustration, boredom or fatigue in connection with the lessons learned.

\section{Positive Relationship between Satisfaction and Positive Academic Emotions}

Based on Table 1, it is known that the correlation value between positive academic emotions with satisfaction that is equal to 0.052 which means there is a positive correlation with the value of Sig. (1-tailed) of 0.321 ( $>0.05$ ) means that the correlation is not significant at the 0.05 significance level. This means that there is no positive correlation between satisfaction with positive academic emotions. There is no correlation in this study, it is suspected there are other factors related to satisfaction and positive academic emotions. Factors related to satisfaction include self-esteem, self-esteem is a state of appreciation that arises from the approval of self-concept achieved by individuals after self-evaluation. Individuals who feel themselves to be incompetent can criticize themselves or can find others truly positive or like themselves. For self-esteem and self-esteem, individuals do not have to have superior quality (Arslan, et al., 2010). Neuman (2014) regards self-esteem as a positive or negative attitude of an individual towards himself. If someone has a positive attitude in self-assessment, his self-esteem will be high; If he has a negative attitude, his self-esteem will be low.

\section{Negative Relationship between Cohesiveness and Negative Academic Emotions}

Based on Table 1, it is known that the correlation between negative academic emotions and cohesiveness is 0.138 which means that both variables have a very low negative correlation. In addition, the value of Sig. (1tailed) of 0.111 (>0.05) means that the correlation is not significant at the 0.05 significance level. This means that there is no negative correlation between cohesiveness and negative academic emotions. According to Yalom (2005) which states that cohesiveness is very important to strengthen individuals in times of conflict that will cause extreme discomfort. The cohesiveness of group members can create warmth, comfort, and a sense of belonging. Cohesiveness is negatively correlated with negative academic emotions, according to Yükselir (2014) negative emotions such as anxiety, anger, shame, hopelessness and boredom are often found especially among students with underperformance results. Anxiety is a state of anxiety, attention disturbances or stress (Paoloni et al., 2014). Embarrassment is related to unpleasant emotions such as shame. Students who experience feelings of shame are students who feel themselves left behind in class or feel shame because they have done something inappropriate (Paoloni et al ., 2014). Hopelessness is related to the lack of hope students have. Students who have feelings of despair are students who are not optimistic to achieve what is desired in class (Paoloni et al., 2014). Boredom refers to unpleasant feelings resulting from feeling tired or bored staying in class. (Paoloni et al., 2014).

\section{Negative Relationship between Cohesiveness and Negative Academic Emotions}

Based on Table 1, it is known that the correlation value between negative academic emotions with competitiveness is equal to 0.199 * which means there is a positive correlation with the value of Sig. (1tailed) of $0.037(<0.05)$ means that the correlation is significant at the 0.05 significance level. This means that there is a positive correlation between competitiveness and negative academic emotions. A positive correlation occurs between the dimensions of competitiveness with negative academic emotions. When viewed from the process of academic emotions, in the process there are controls related to cognition that can focus directly on cause-and-effect relationships (eg expectations of action-results) and indirectly refer to conditional relations between personal characteristics and contingency outcomes. Control-related perceptions is one of the most important types of cognition for assessing one's competence or competitiveness, or also referred to as perceived competitiveness (for example, self-concept ability and selfefficacy expectations). Subjective values involved in self-appraisal can be intrinsic or extrinsic, for example when students get good grades might be appreciated by other students who will intrinsically motivate students to achieve them, and may also be very important for other students who are motivated by extrinsic goals such as how the value obtained will help to get a good job in the future. Subjective-control and 
subjective values are proposed to mediate the relationship between emotional experience and environmental aspects specifically related to (a) competence support, (b) autonomy support versus control, (c) achievement expectations and goal structures, (d) achievement outcomes and feedback, and (e) social relatedness. Student emotions can influence their cognitive assessments so they better assess their own competencies when they experience positive academic emotions. In this case, emotions can be considered as antecedents of aspects in a student's social environment (Goetz, et al., 2006).

\section{Positive Relationship between Friction and Negative Academic Emotions}

Based on Table 1, it is known that the correlation between negative academic emotions and friction is 0.148 which means there is a positive correlation with the Sig. (1-tailed) of $0.094(>0.05)$ means that the correlation is not significant at the 0.05 significance level. This means that there is no positive correlation between friction with negative academic emotions. There is no correlation in this study, it is suspected there are other factors related to conflict (friction). As explained earlier, conflicts (friction) often occur among students with low levels of resilience and this is an ability to overcome the most difficult problems and overcome the most complex situations. This represents a person's capacity to tolerate an event or disaster that occurs. Resilience allows people to overcome the problems that occur in them and overcome these complex situations (Isaacson, 2002). Examples of statements related to conflict are that some students in my class often fight and some students in my class are enemies.

\section{Negative Relationship between Satisfaction and Negative Academic Emotions}

Based on Table 1, it is known that the correlation value between negative academic emotions with satisfaction that is equal to -0.201 * means there is a negative correlation with the value of Sig. (1-tailed) of $0.036(<0.05)$, meaning that there is a negative correlation between satisfaction and negative academic emotions. Satisfaction (satisfaction) is at the highest level when students feel that activities in the classroom are well organized and the teacher is very supportive and allows students to be actively involved in their learning (Radovan \& Makovec, 2015). Based on the results of research Kolak \& Reflection (2015) revealed that satisfaction is an emotional response to reduce boredom and despair. Boredom and hopelessness are included in the example of negative academic emotions, hopelessness related to lack of hope. Students who have feelings of despair are those who do not hope optimistically to achieve what is desired in class (Paoloni et al., 2014). Boredom refers to the unpleasant feeling of feeling tired or tired of staying in class. Generally a natural situation is felt which makes it difficult to pay attention or participate in the tasks requested. Students who are bored in class have problems in paying attention, concentrating, finding meaning from assignments, working hard, and overcoming difficulties (Paoloni et al., 2014).

\section{Conclusion}

Based on the results of hypothesis testing to look for correlations between perception of classroom learning environment and academic emotions in 81 junior high school respondents in the city of Bandung, it can be concluded that the results of the correlation between the dimensions of competitiveness with negative academic emotions there is a positive correlation at low levels. That is, the higher the competitiveness (competitiveness) experienced by students, the tendency of students to experience negative academic emotions will be high, and vice versa. In the results of the correlation between the dimensions of satisfaction (satisfaction) with negative academic emotions there is a negative correlation at a low level. It means, the higher students experience satisfaction, the tendency of students to experience negative academic emotions tends to be low, and vice versa.

\section{References}

Abolmaali, K., \& Mahmudi, R. (2013). The Prediction of Academic Achievement Based on Resilience and Perception of the Classroom Environment. Open Science Journal of Education, 1(1), 7-12. Retrieved from http://www.openscienceonline.com/jo urnal/edu

Amirul, N. J., Nidzam, C., \& Ahmad, C. (2011). The physical classroom learning environment.

Anttila, H., Pyhältö, K., Pietarinen, J., \& Soini, T. (2017). From anxiety to enthusiasm : emotional patterns among student teachers. European Journal of Teacher Education, 40(4), 117.http://doi.org/10.1080/02619768.2017.1349095

Arslan, C., Hamarta, E., \& Uslu, M. (2010). The relationship between conflict communication , self- esteem and life satisfaction in university students, 5(January), 31-34. 
Berns, R. (1997). Child, Family, School, Community Social and Support. Harcourt Brace College Publishers.

Deci, E. L., Olafsen, A. H., \& Ryan, R. M. (2017). Self-Determination Theory in Work Organizations : The State of a Science.

Cicchetti, D. (2014). NIH Public Access, 54(4), 402-422. http://doi.org/10.1111/j.14697610.2012.02608.x.Annual

Fraser, B. J. (1998). Classroom environment instruments: development, validity $\quad$ and applications, 7-33.

Frenzel, A. C., Pekrun, R., \& Goetz, T. (2007). Perceived learning environment and students' emotional experiences: A multilevel analysis of mathematics classrooms. Learning and Instruction, 17(5), 478-493. http://doi.org/10.1016/j.learninstruc.2 007.09.001

Gentry, M., \& Gable, R. K. (2001). From the student's perspective-My Class Activities: An instrument for use in research and evaluation. Journal for the Education of the Gifted, 24(4), 322-343. Retrieved from http://ovidsp.ovid.com/ovidweb.cgi?T=JS\&PAGE=reference\&D=psyc3\&N $\quad$ EWS=N\&AN=200105017-002

Goetz, T., Pekrun, R., Hall, N., \& Haag, L. (2006). Academic emotions from a social-cognitive perspective: Antecedents and domain specificity of students ' affect in the context of Latin instruction Copyright (C) The British Psychological Society. The British Psychological Society, 289-308.

Gomes, C. F. A., Brainerd, C. J., \& Stein, L. M. (2013). Effects of Emotional Valence and Arousal on Recollective and Nonrecollective Recall, 39(3), 663-677. http://doi.org/10.1037/a0028578http://doi.org/10.1348/000709905X42860

Greensfeld, H., \& Nevo, E. (2017). To use or not to use, that is the question : On students ' encounters with a library of examples. Cogent Social Sciences, 7(1), 1-25. http://doi.org/10.1080/23311886.2017.1323381

Hill, L. M., \& Mobley, J. A. (2015). Making the Change From Elementary to Middle School.

Holodynski, M. (2013). The Internalization Theory of Emotions : A Cultural Historical Approach to the Development of Emotions The Internalization Theory of Emotions : A Cultural Historical Approach to the Development of Emotions, (March), 37-41.

Kamenopoulou, L. (2016). Ecological Systems Theory : a valuable framework for research on Inclusion and Special Educational Needs / Disabilities, 88(4), 515-527.

Kolak, A., \& Reflection, T. (2015). Didactic culture of school and students 'emotional responses (related to the teaching process ), 8(2), 73-80.

Lam, U. F., Chen, W.-W., Zhang, J., \& Liang, T. (2015). It feels good to learn where I belong: School belonging, academic emotions, and academic achievement in adolescents. School Psychology International, 36(4),393-409.http://doi.org/10.1177/0143034315589649

Langton, Robbins, \& Judge. (2010). Organizational Behavioiur. Canada: Pearson Education.

Lawler, E. J., \& Thye, S. R. (2000). Emotion and Group Cohesion in Productive Exchange.

Lens, W., Lacante, M., Vansteenkiste, M., \& Herrera, D. (2005). Study persistence and academic achievement as a function of the type of competing tendencies. European Journal of Psychology of Education, 20(3),275-287.http://doi.org/10.1007/BF03173557

Mujahidah. (2015). Implementasi Teori Ekologi Bronfenbrenner dalam Membangun Pendidikan Karakter yang Berkualitas. Lentera, IXX(2), 171-185.

Neuman, W. L. (2014). Social Research Methods: Qualitative and Quantitative Approaches. Relevance of social research (Vol. 8). http://doi.org/10.2307/3211488

Padron, Y. N., Waxman, H. C., \& Lee, Y.- H. (2012). Classroom learning environment differences between resilient, average, and nonresilient middle school students in reading. Education and Urban Society, 46(2), 264-283. http://doi.org/10.1177/001312451244 6217

Paoloni, P. V., Vaja, A. B., \& Muñoz, V. L. (2014). Reliability and Validity of the-Achievement Emotions Questionnairell:A Study of Argentinean University Students. Electronic Journal of Research in Educational Psychology, 12(3), 671- 692.

Papalia, D. E., Ods, S. W., \& Feldman, R.D. (2008). Human Development (Psikologi Perkembangan). Jakarta: Kencana.

Pekrun, R., Goetz, T., Frenzel, A. C., Barchfeld, P., \& Perry, R. P. (2011). Measuring emotions in students' learning and performance: The Achievement Emotions Questionnaire (AEQ). Contemporary Educational Psychology,36(1), 36-48. http://doi.org/10.1016/j.cedpsych.201 0.10.002

Pekrun, R., Goetz, T., Titz, W., \& Perry,R. P. (2002). Positive Emotions in Education. Beyond Coping: Meeting Goals, Visions and Challenges, 149- 173. http://doi.org/10.1207/S15326985EP3 702 
Pekrun, R., Lichtenfeld, S., Marsh, H. W., \& Goetz, T. (2017). Achievement Emotions and Academic Performance: Longitudinal Models of Reciprocal Effects, $0(0), \quad 1-18$. http://doi.org/10.1111/cdev.12704

Radovan, M., \& Makovec, D. (2015). Adult Learners ' Learning Environment Perceptions and Satisfaction in Formal Education - Case Study of Four East-European Countries, $\quad$ 8(2). 101-112. http://doi.org/10.5539/ies.v8n2p101

Rita, P., \& Paola, V. (2014). Emotions in Academic Contexts. Theoretical perspectives and implications for educational practice in college. Emociones En Contextos académicos.Perspectivas Teóricas E Implicaciones Para La Prácticaeducativa En La Universidad., 12(3), 567-596.

Santrock, J. W. (2007). Remaja. Jakarta: Erlangga.

Scholae, O. (2013). Emotional Aspects of Learning and Teaching: Reviewing the Field - Discussing the Issues To máš Janí k. Orbis Scholae, 7(2).

Sink, C., \& Spencer, L. (2016). My Class Inventory-Short Form as an Accountability Tool for Elementary School Counselors to Measure Classroom Climate, 9(1), 37-48.

Tshewang, R. (2015). Bhutanese Eight Grade Students‘ and Teachers‘ Perceptions Of Their Classroom Learning Environment In Relation To The New Mathematics Curriculum.

Villavicencio, F. T. (2011). Critical thinking, negative academic emotions, and achievement: A meditational analysis. The Asia- Pacific Education Researcher, 1(August), 118-126.

Wang, M.-T., \& Holcombe, R. (2010). Adolescents' perceptions of school environment, engagement, and academic achievement in middle school. American Educational Research Journal, 47(3), 633-662. http://doi.org/10.3102/000283120936 1209

Wei, L., \& Elias, H. (2011). Relationship between Students' Perceptions of Classroom Environment and Their Motivation in Learning English Language. International Journal of Humanities and Social Science, 1(21), 240-250.

Yalom, I. D. (2005). The Theory and Practice of Group Psychotherapy EDITION. United States of America: Basic Books.

Yükselir, C. (2014). An Analysis of the Perceptions on Academic Emotions and Emotional Experiences in English, 2(2), 269-278. http://doi.org/10.5296/ijele.v2i2.6617

Zadra, J. R., \& Clore, G. L. (2012). Emotion and Perception: The Role of Affective Information, 1-16. http://doi.org/10.1002/wcs.147.Emotions 